\title{
Chapter 28 \\ Teacher Professional Development at Scale in the Global South
}

\author{
Cher Ping Lim, Victoria Tinio, Matthew Smith, Ellen Wenting Zou, \\ and Justin Edward Modesto III
}

UNESCO (2016) estimated that 68.8 million teachers need to be recruited and trained to achieve Sustainable Development Goal 4, ensuring inclusive and equitable quality education and promoting lifelong learning opportunities for all by the year 2030 . The problem of a lack of qualified teachers is acute in the Global South, where countries often struggle with limited resources and significant rural-urban, regional, gender, and other gaps in the provision of quality education. The shortage of qualified teachers affects student learning engagement, reducing the effectiveness of schooling (Verspoor 2004; OECD 2005; Hanushek 2005; Rivkin et al. 2005; UNESCO 2006). To address this problem, countries in the Global South have to provide high-quality teacher professional development to all teachers, from pre-service to induction to in-service.

\section{P. Lim (凶)}

Faculty of Education and Human Development, Learning Technologies and Innovation, The Education University of Hong Kong, Hong Kong, China

e-mail: clim@eduhk.hk

\section{Tinio}

Foundation for Information Technology Education and Development, Manila, Philippines

\section{Smith}

International Development Research Centre, Ottawa, Canada

E. W. Zou

The University of Texas, Austin, TX, US

J. E. Modesto III

Foundation for Information Technology Education and Development, Manila, Philippines

B. Panth and R. Maclean (eds.), Anticipating and Preparing for Emerging Skills and Jobs, Education in the Asia-Pacific Region: Issues, Concerns and Prospects 55, https://doi.org/10.1007/978-981-15-7018-6_28 


\section{Equity, Quality, and Efficiency Challenges for Teacher Professional Development}

The TPD@Scale Coalition for the Global South was initiated in 2018 to promote quality, equitable, and sustainable large-scale, information and communications technology (ICT)-mediated teacher professional development (TPD) through collaboration, research, and implementation support. To provide equitable access to TPD, programs need to be fair and inclusive. Fairness refers to personal and social circumstances not being a barrier to achieving education potential, while inclusivity means that all individuals, regardless of personal and social circumstances, can achieve a minimum level of education (OECD 2005). To design high-quality TPD programs, collaborative, active learning experiences should be provided, and teachers need to be supported by constant modeling, coaching, and expert feedback over a sustained duration. Efficiency can be defined in terms of the optimization of inputs (teachers, administrators, other human resources, physical facilities, materials, instructional methods, teacher training, etc.) to produce the desired outputs (learning gains).

\section{Addressing the Challenges with TPD@Scale}

Students' academic success is highly correlated with the quality of teaching, and professional development is a key ingredient in schools and school systems for improving teaching quality (OECD 2005). Hence, providing inclusive, quality, and cost-effective TPD programs for teachers in the Global South is a particularly high priority. Despite a global need for quality teachers, most teachers in the Global South receive inadequate and often ineffective professional development that fails to develop their core competencies in teaching. In many countries, the frequency of professional development is episodic, the quality varies, the duration is limited, and ongoing support or follow-up is extremely rare (Ball and Cohen 2000; Borko 2004). Teachers in the poorest and most fragile countries and regions, who need professional development and support, often receive the least.

TPD@Scale seeks to address this need for inclusive, quality, and cost-effective TPD programs in the Global South. It taps into the potential of ICT to benefit large numbers of teachers, whether remotely, face-to-face, or both, and to expand the coverage and simultaneously ensure the depth of change necessary to support and sustain teachers' professional learning. Massive open online courses (MOOCs), open courseware, intelligent tutoring systems, learning games, and a variety of peer learning networks and collaborative communities are among the emerging technologies mediating TPD. 


\section{Examples of Existing Practices}

In this section, we will introduce two cases and describe how ICT supports large-scale TPD programs to achieve equity, quality, and efficiency.

\section{TESS-India}

In 2012, the Open University (OU) in the United Kingdom launched the Teacher Education through School-based Support in India, or TESS-India, designed by experts from the $\mathrm{OU}$ and state resource group members. The program adopts a blended model, combining the learning from MOOCs and from facilitators' feedback on the peer-reviewed assignments (Figure 28.1). Each MOOC runs for approximately $4 \mathrm{~h}$ per week over a 6 -week period. When participants successfully complete a certain number of assignments, they are awarded a Certificate of Completion. The first pilot of the MOOC, in English, was offered in May to July 2015 with almost 3000 participants.

As teachers are more used to face-to-face learning, the MOOCs are also supplemented by weekly or fortnightly contact courses. These contact courses are conducted either in district institutes of education and training, teacher education institutions, or secondary schools, led by a local facilitator who has successfully finished the MOOC. The contact class aims to serve as an alternative venue for peer-supported group study as well as to provide access to quality TPD for participants who have

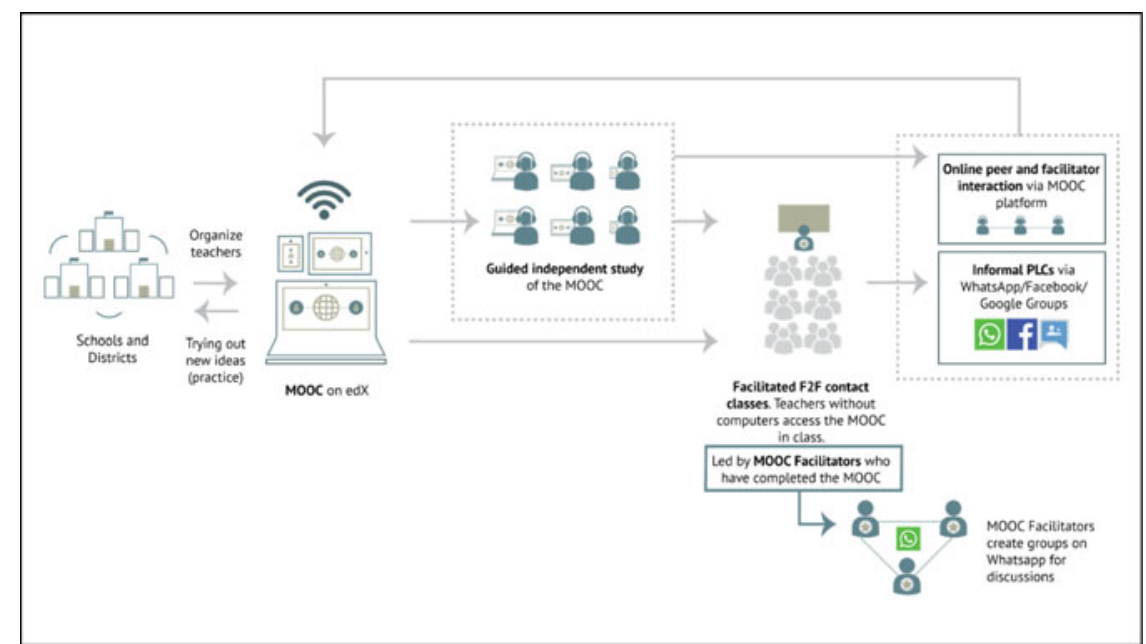

Source: Lim, C.P. (2019, August). TPD@Scale Coalition for the Global South. 8th International Skills Forum: Future of Skills and Jobs in the Age of Digital Disruptions. Presentation at the Asian Development Bank, Mandaluyong City, Philippines.

Figure 28.1 TPD@Scale model: TESS-India 
no internet or computer. It is found that completion rates were especially high $(80 \%)$ for areas with learner support through face-to-face classes.

Besides meeting face-to-face, teachers also form informal professional learning communities using social media and messaging applications such as WhatsApp, Facebook, and Google Groups. MOOC facilitators also used WhatsApp to share experiences and resolve issues they have encountered in the contact class and in the MOOCs.

In terms of assessment of learning, concerns were expressed about the peer review mechanism where the peer review tasks were allocated randomly. Participants were often frustrated by the poor quality of peer feedback. To address this issue, the grading function was removed, and the feature focused more on the formative feedback that peers provide.

In general, connectivity is less an issue in the program, with more technological infrastructures being invested and promoted by the Government of India. The MOOCs are relatively inclusive. However, time constraints and gender-related involvement are the major obstacles to participation. For instance, more senior female teachers may have domestic duties that prevent them from participating or finishing the MOOCs more actively.

Unlike TESS-India, access to the Internet and technology is still a major barrier that hinders the implementation of quality and cost-effective TPD@Scale in the Global South. The Philippines faces such a barrier in internet connectivity. In 2015, with funding from the United States Agency for International Development USAID, the Foundation for Information Technology Education and Development initiated an intervention to develop a TPD delivery model as an alternative to the Education Department's traditional train-the-trainer cascade model (e.g., 10-day face-to-face workshop) to reach the entire teaching staff of then around 600,000 teachers in a cost-effective and timely manner. The pilot involved 240 rural, peri-urban, and urban primary schools, and reached 4040 Kindergarten to 3rd grade ( $\mathrm{K}$ to 3 ) teachers of early language literacy and numeracy.

The blended TPD@Scale model of Early Language Literacy and Numeracy (ELLN) Digital (Figure 28.2) features teachers' individual offline learning through courseware requiring classroom application of concepts learned, with self-assessments.

Teachers' independent learning was supplemented by peer support through Learning Action Cells (LACs), a form of PLC mandated by the Department of Education. Groups of teachers, consisting of 2 up to a maximum of 15 individuals, meet regularly to reflect on and discuss the course content from the Compact Disc (CD), which they had studied and applied in class. These group interactions are organized by the school head and/or master teachers and led by teachers who are designated LAC facilitators. The LAC sessions are meant for teachers to share their learning in a collegial community. LAC facilitators are not meant to be experts delivering lectures and providing all the answers to solve their peers' problems.

Ninety-five percent of the participants completed some or all of the course modules by the end of the pilot. There were small but significant gains in pedagogical and content knowledge and learning, especially among rural school teachers. 


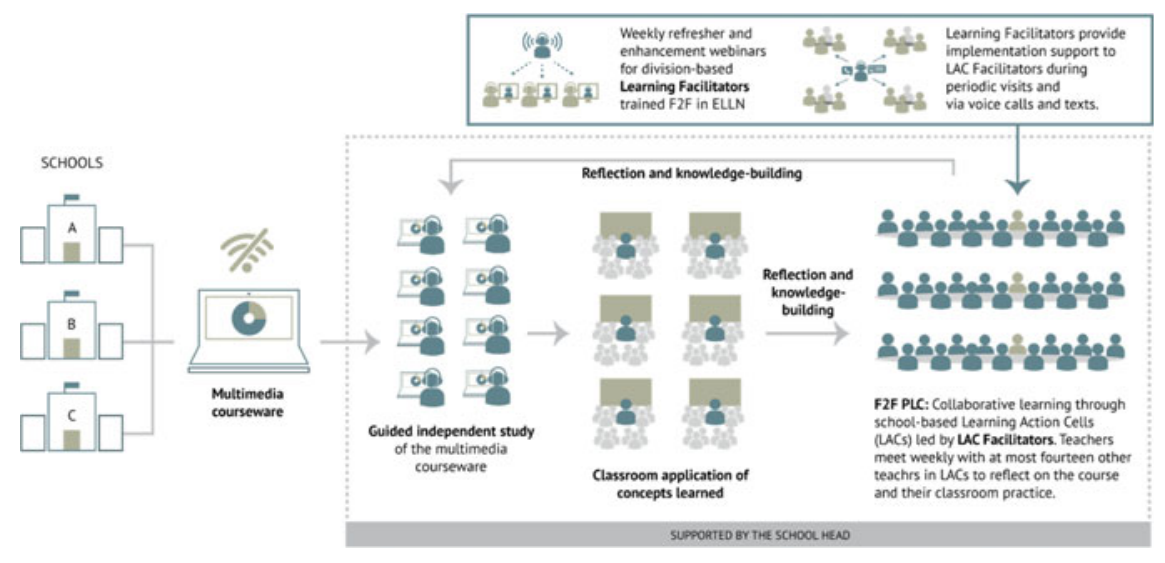

Figure 28.2 TPD@ Scale model of Early Language Literacy and Numeracy (ELLN) Digital

However, there remain some challenges. According to the program evaluation, some teachers experienced difficulties in engaging with the learning materials due to time constraints and limited access to the technology and courseware; and some teachers were unable to apply what they had learned to their teaching practice because of insufficient classroom resources. Another challenge is assessment. Even if teacher knowledge has improved, it is hard to know whether the teachers' practice has been transformed and how much change has occurred, given the limited knowledge gained from the teachers' self-reported data.

The ELLN Digital model also highlights the tensions of equity, quality, and efficiency. Although the pilot was implemented with more than 4000 teachers in various contexts, all K-3 teachers will be required to take the course as part of the national rollout, beginning SY 2020-2021. The Department of Education is working to ensure teachers' access to the program without any major obstacles. Now the focus shifts to maintaining quality across a wide array of different contexts. The original ELLN Digital content was reviewed by a team of experts to ensure fidelity to the DepEd training curriculum. Access to the standard expertise in the courseware provided consistency across learners participating in the program, which was difficult to achieve under the original cascade model of ELLN. In terms of cost-effectiveness, though it was time-consuming and fairly expensive to develop the blended learning materials, the cost was one-off, and DepEd can benefit from this endeavor if the course is able to run across the whole country (now 600,000 K-3 teachers) in the next few years. 


\section{Critical Issues}

In studying these models of TPD@Scale, three critical issues have emerged in the implementation of quality, accessible, and cost-effective TPD.

Learner Differentiation or Personalization. This refers to designing and implementing programs that suit or accommodate teachers or teacher groups in specific contexts. Accordingly, this can imply that teachers need to be included in the conceptualization and testing processes of the @ scale model in order to appropriately and continually refine the features of the TPD program, based on their feedback. The learning experience should also provide options for adaptation. In the pursuit of equity, the program must have features that can adjust to fulfill teachers' individual needs as learners.

Learner Support. This refers to access to resources and tools post-training. Once the program has ended, the lack of validation and feedback can cause inconsistent, if not ineffective, implementation or translation of the competencies gained from the TPD. Support mostly includes mentoring and coaching, but this can also pertain to access to professional learning communities or peers who had gone through the same learning experience.

Assessment. This refers to a formal process of obtaining and analyzing data to measure learning. Quality formative and summative assessments become a challenge, if not infeasible when done for TPD programs at scale, particularly for models that are blended and do not solely rely on face-to-face classes. As an alternative, although there are some studies correlating student performance with a teacher's participation in TPD, researchers have found it difficult to directly attribute student learning outcomes to effective TPD. As with personalization, there are multiple factors and contexts to consider in designing assessment for TPD@ Scale.

Such critical issues straddle the tensions of quality, equity, and efficiency. To date, there has been no large body of scholarly work thoroughly studying the issues of personalization, support, and assessment in TPD@Scale in the Global South. In response to this, a large part of the Coalition's research work is to provide technical assistance (i.e., support in the design and development of their TPD@Scale system) to governments facing these critical issues and to document (1) their scaling process and (2) their learning (e.g., challenges faced and outcomes reached based on the specific contexts).

\section{Conclusion}

From the preliminary analysis of the current practices of TPD@ Scale, it is apparent that ICT has the potential to address some of the challenges of large-scale TPD in the Global South. However, many questions remain unanswered, such as, how can teachers be motivated and facilitated to learn digitally? What are the best pedagogies for MOOCs for TPD@Scale? How can evaluation design be improved to capture 
teacher learning and/or trace learner outcomes and attribute them to TPD@Scale interventions? How can ICT cost-effectively increase coaching opportunities for TPD@Scale? How can you address the issues of personalization, support, and assessment in a cost-effective manner and without sacrificing the quality of the learning design? A carefully planned evaluation agenda is needed to collect data to answer these questions. There is also a need for more studies of TPD for disadvantaged and marginalized groups. A comprehensive analysis based on more rigorous data from the existing practices will go a long way to ensure the achievement of equity, quality, and efficiency of TPD@Scale programs across the Global South.

Links to the presentation materials: https://events.development.asia/materials/201 90828/tpdscale-coalition-global-south. https://events.development.asia/materials/ 20190828/philippines-case-study-elln-digital.

\section{References}

Ball, D. L., \& Cohen, D. K. (2000). Developing practice, developing practitioners: Toward a practicebased theory of professional education. In L. Darling-Hammond \& G. Sykes (Eds.), Teaching as the learning profession (pp. 3-31). San Francisco: Jossey-Bass.

Borko, H. (2004). Professional development and teacher learning: Mapping the terrain. Educational Researcher, 33(8), 3-15.

Hanushek, E. A. (2005). Economic outcomes and school quality 2005. Paris and Brussels: The International Institute for Educational Planning and International Academy of Education.

OECD. (2005). Teachers matter: Attracting, developing and retaining effective teachers. Paris: Organisation for Economic Co-operation and Development.

Rivkin, S., Hanushek, E., \& Kain, J. (2005). Teachers, schools, and academic achievement. Econometrica, 73(2), 417-458.

UNESCO Institute for Statistics. (2006). Teachers and educational quality: Monitoring global needs for 2015. Montreal: UNESCO, International Institute for Educational Planning.

UNESCO Institute for Statistics. (2016). The World needs almost 69 million new teachers to reach the 2030 Education goals. Retrieved from https://unesdoc.unesco.org/ark:/48223/pf0000246124.

Verspoor, A. (2004). The challenge of learning: Improving the quality of basic education in subSaharan Africa. Paris: Association for the Development of Education in Africa. 
The views expressed in this Chapter are those of the authors and do not necessarily reflect the views and policies of the Asian Development Bank (ADB) or its Board of Governors or the governments they represent.

ADB does not guarantee the accuracy of the data included in this Chapter and accepts no responsibility for any consequence of their use. The mention of specific companies or products of manufacturers does not imply that they are endorsed or recommended by ADB in preference to others of a similar nature that are not mentioned.

By making any designation of or reference to a particular territory or geographic area, or by using the term "country" in this Chapter, ADB does not intend to make any judgments as to the legal or other status of any territory or area.

This work is available under the Creative Commons Attribution 3.0 IGO license (CC BY 3.0 IGO) https://creativecommons.org/licenses/by/3.0/igo/. By using the content of this Chapter, you agree to be bound by the terms of this license. For attribution, translations, adaptations, and permissions, please read the provisions and terms of use at https://www.adb.org/terms-use\#openac cess.

This CC license does not apply to non-ADB copyright materials in this Chapter. If the material is attributed to another source, please contact the copyright owner or publisher of that source for permission to reproduce it. ADB cannot be held liable for any claims that arise as a result of your use of the material.

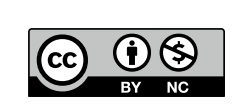

